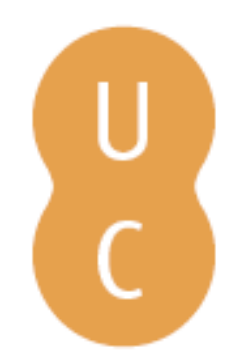

\title{
pompalina
}

\section{O hipervídeo na educação online: pensando a autoria de vídeos interativos}

Autor(es): $\quad$ Martins, Vivian; Santos, Edméa

Publicado por: Imprensa da Universidade de Coimbra

URL

persistente: URI:http://hdl.handle.net/10316.2/47384

DOI: $\quad$ DOI:https://doi.org/10.14195/978-989-26-1716-9_8

Accessed : $\quad$ 26-Apr-2023 15:40:48

A navegação consulta e descarregamento dos títulos inseridos nas Bibliotecas Digitais UC Digitalis, UC Pombalina e UC Impactum, pressupõem a aceitação plena e sem reservas dos Termos e Condições de Uso destas Bibliotecas Digitais, disponíveis em https://digitalis.uc.pt/pt-pt/termos.

Conforme exposto nos referidos Termos e Condições de Uso, o descarregamento de títulos de acesso restrito requer uma licença válida de autorização devendo o utilizador aceder ao(s) documento(s) a partir de um endereço de IP da instituição detentora da supramencionada licença.

Ao utilizador é apenas permitido o descarregamento para uso pessoal, pelo que o emprego do(s) título(s) descarregado(s) para outro fim, designadamente comercial, carece de autorização do respetivo autor ou editor da obra.

Na medida em que todas as obras da UC Digitalis se encontram protegidas pelo Código do Direito de Autor e Direitos Conexos e demais legislação aplicável, toda a cópia, parcial ou total, deste documento, nos casos em que é legalmente admitida, deverá conter ou fazer-se acompanhar por este aviso. 

VIVIAN MARTINS

Instituto Federal de Educação, Ciência e Tecnologia do Rio de Janeiro (IFRJ).

vivian.martinst@gmail.com.

EDMÉA SANTOS

Universidade Federal Rural do Rio de Janeiro - Líder do Gpdoc

- Grupo de Pesquisa Docência e Cibercultura

edmeabaiana@gmail.com.

\section{O HIPERVÍDEO NA EDUCAÇÃO ONLINE: PENSANDOA AUTORIA DE VÍDEOS INTERATIVOS}

\section{Para Começo de Conversa}

Os vídeos contemporâneos perderam a exclusividade da contemplação e nos chamam à ação. Além da ação do usuário, sua própria ação reagindo, chamando para a prática. Os hipervídeos são exemplos desse fenômeno, é um gênero de cibervídeo em crescente expansão, demonstrando potenciais para a educação online. Entendemos cibervídeos como os vídeos produzidos na cibercultura e não aos gêneros audiovisuais de forma abrangente.

Com a possibilidade de associar mídias ao vídeo original, o usuário passa a ter acesso a saberes outros, proporcionando uma aprendizagem personalizada e colaborativa, em sintonia com as dinâmicas da cibercultura. O objetivo principal do hipervídeo é que ele possa ser assistido de diferentes perspectivas, independente de sequência, mídias selecionadas ou linearidade, sendo esse o ponto alto do gênero.

Um dos gêneros que mais acrescentam características próprias da cibercultura, o hipervídeo se destaca por apresentar interatividade, hipertexto e hipermídia. Concordamos com Silva (2003) em sua análise sobre interatividade e bebemos dessa fonte para relacioná-la com o cibervídeo: "[...] na perspectiva da interatividade, é preciso que o suporte informacional 
disponha de flexibilidade, de disposições para a intervenção do usuário" (Silva, 2003, p.1).

Para trabalhar com a autoria de hipervídeos acionamos o dispositivo ${ }^{1}$ de pesquisa Oficina de Produção de Cibervídeos, de modo a oportunizar aos praticantes $^{2}$ ciberculturais a noção de que os vídeos são dispositivos de aprendizagens múltiplas, mostrando a potência que a linguagem audiovisual tem na educação contemporânea. $\mathrm{O}$ método selecionado foi a pesquisa-formação na cibercultura (Santos, 2014) e o campo de pesquisa aconteceu na disciplina Tecnologias e Educação, do primeiro período da licenciatura em Pedagogia da Universidade do Estado do Rio de Janeiro (UERJ).

O objetivo geral é compreender como os vídeos vêm se materializando e circulando na educação online, desenvolvendo práticas para a produção de gêneros de cibervídeos. Como resultado emergiu a noção subsunçora autoria de vídeos interativos, abordada a partir de reflexões sobre interatividade. Desta forma, buscamos a formação de pedagogos implicados com o audiovisual na educação da atualidade.

O presente texto foi desenvolvido em tópicos específicos: na seção 1, esta introdução, apresentando o objeto de pesquisa, o método e o dispositivo; na seção 2, contextualizando o hipervídeo na educação online; na seção 3, os cotidianos da pesquisa-formação na cibercultura; na seção 4, a emergência da noção subsunçora a partir das experiências vivenciadas na Oficina de Produção de Cibervídeos; e na seção 5, algumas considerações conclusivas.

\section{O Hipervídeo e a Educação Online}

O hipervídeo é um vídeo interativo que permite diálogo com o usuário, por meio de hiperligações internas ou externas ao vídeo principal. O vídeo pode apresentar, por exemplo: sites, apresentações, imagens, mapas conceituais,

1 "Assumimos o conceito de dispositivo a partir de Ardoino (2003), para quem os dispositivos são modos e meios utilizados pelos sujeitos para expressar noções necessárias ao pesquisador para compreender os fenômenos." (Martins, 2017, p. 16)

2 "Termo de Certau (1994) para aquele que vive as práticas/táticas cotidianas." (Alves, 2008, p. 10) 
outros vídeos, zonas clicáveis diversas, widgets $^{3}$, perguntas múltipla escola ou discursivas. Autores como Bettencourt (2009) e Saraiva (2013) relacionam o conceito de hipervídeo ao hipertexto, como podemos ver a seguir:

O conceito de hipervídeo remete para o conceito de hipertexto, quando aplicado aos tipos de informação dinâmicos, como vídeo e áudio. Uma vez que permite navegação e modificação da informação, assim como a sua partilha, assemelha-se mais a um processo distribuído e fragmentado do que a um fenómeno centralizado. Ou seja, de um ponto de vista teórico, aproxima-se da forma como se considera que o cérebro funciona (Saraiva, 2013, p. 166).

É neste contexto, o do hipermédia, que se insere o conceito do hipervídeo, ou seja, o vídeo interactivo com links integrados para imagens, texto, URLs ou mesmo outros vídeos (Bettencourt, 2009, p. 12).

Os dois autores citados pensam além da relação entre hipertexto e hipervídeo e colocam a questão espacial e a temporal como diferenças para os dois conceitos, possuindo o último uma dinâmica ativa, enquanto o hipertexto retrata ligações estáticas. Por este motivo, Saraiva (2013) destaca que a grande diferença entre o hipertexto e o hipervídeo é a questão temporal, pois o hipervídeo não se esgota em um clique, ele tem a capacidade de interligar incontáveis sequências. Depois de navegar dentro do vídeo, o usuário exterioriza, partindo para outras conexões, demonstrando a dinâmica temporal.

A relação com o hipertexto é embrionária, pode-se entender que é a partir desse conceito que surgem os hipervídeos, mas eles não têm exatamente as mesmas características. Bettencourt (2009) destaca o ano de 1967 como marco introdutório: "Considera-se "Kinoautomat", de Radúz Činčera, o primeiro filme interactivo, ou seja, a primeira amostra do que viria a ser considerado o hipervídeo." (Bettencourt, 2009, p. 32) A autora conta que a audiência possuía botões de sim ou não para escolher opções alternativas para o filme.

3 Widget é um elemento de interface gráfica do usuário que inclui janelas, botões, menus, ícones, barras de rolagem e outros. Fonte: https://pt.wikipedia.org/wiki/Widget 
No Brasil, foi criado em 1992 o nacionalmente famoso Você Decide, da Rede Globo, com formato semelhante. A diferença consistia na forma como os espectadores selecionavam a opção (eles escolhiam o final da história por meio de chamadas telefônicas). Em ambos os casos, a interação era limitada e o sistema simplificado, permitindo somente duas opções (sim ou não). A evolução da internet refletiu no hipervídeo, permitindo visualizar outros usos, com conteúdos online, sistemas comunicacionais ou outros vídeos em momentos (quebras) específicos (as) dentro do vídeo inicial.

As vantagens do hipervídeo para a educação online são consistentes, a aceitabilidade e a personalização são argumentos importantes. A grande quantidade de informação disponibilizada em rede e a maneira como interagimos com ela estão - cada vez mais velozes. A dinâmica da aprendizagem se modifica de forma gradual. Atualmente ocorre de forma não linear, ou seja, com mudanças constantes entre diversos textos ou conteúdos disponibilizados, principalmente com os leitores imersivos, indo ao encontro dos atributos do hipervídeo, facilitando a sua implantação em ambientes educacionais.

No hipervídeo, a informação também aparece distribuída, quer por integrar diferentes meios de informação, quer pela fragmentação dessas informações. Esta fragmentação é organizada pelos utilizadores através das explorações que efetuarem. Para tal, é necessário desenvolver diretivas próprias para o design (Saraiva, 2013, p. 167).

A personalização é o outro argumento que reconhece a vantagem do hipervídeo na educação online. O hipervídeo possibilita que o usuário escolha qual caminho percorrer para chegar ao final, personalizando de acordo com o seu estilo de aprendizagem. Uma potencialidade pedagógica é a possibilidade de inserir perguntas objetivas ou discursivas. Dependendo da resposta, pode-se programar para o vídeo tomar uma ou outra direção. Se a resposta for correta, o vídeo seguirá; se a resposta for incorreta, retornará para algum ponto ou então será inserido outro recurso com uma forma de explicação diferente.

Se desejar criar um hipervídeo, o educador pode recorrer, por exemplo, ao site Hapyak ${ }^{4}$, para dotá-lo de mais funcionalidades como formulários,

\footnotetext{
4 Acesso gratuito em: https://corp.hapyak.com/.
} 
questões, botões, imagens, textos e ramificações, ou editá-lo no âmbito do YouTube $^{5}$, de forma mais superficial, incluindo direcionamento para vídeos, imagens, textos e hiperlink para qualquer conteúdo em rede, dependendo da necessidade ou interesse do idealizador. O usuário pode iniciar com experimentações pelo YouTube, no momento de edição e compartilhamento, por ser intuitivo e acessível, passando para editores sofisticados e com mais recursos disponíveis.

Pensar a educação online como "o conjunto de ações de ensino-aprendizagem, ou atos de currículo mediados por interfaces digitais que potencializam práticas comunicacionais interativas, hipertextuais e em mobilidade”, (Santos, 2014, p. 63) é poder relacioná-la diretamente ao hipervídeo, que apresenta qualificação de multimídia com elementos de hipertexto. Apesar de ainda ser pouco explorado na educação online, há um enorme potencial, visto que compõe múltiplos recursos pedagógicos que favorecem os processos de aprendizagemensino ${ }^{6}$ em rede.

\section{A Pesquisa-Formação na Cibercultura}

A pesquisa de mestrado em Educação (PROPED/UERJ) intitulada "Os cibervídeos na educação online: uma pesquisa-formação na cibercultura" (Martins, 2017) buscou mapear os gêneros produzidos a partir da tecnologia digital em rede, principalmente os vídeos potenciais para a educação online, destacando sete gêneros de cibervídeos: hipervídeo, microvídeo, videoaula, videoconferência, vídeo instantâneo, vídeo volátil e webinar. A partir desse estudo exploratório delineou-se o momento prático da pesquisa.

Na segunda etapa, após compreender e se apropriar desse fenômeno da cibercultura, entramos em campo com praticantes da disciplina Tecnologias e Educação da graduação em Pedagogia da Universidade do Estado do Rio

5 Acesso gratuito em https://www.youtube.com/.

6 A presente forma de escrita busca superar dicotomias impostas pela ciência moderna para termos importantes ao entendimento de pesquisa que adotamos. 
de Janeiro (UERJ) e acionamos o dispositivo de pesquisa principal ${ }^{7}$ Oficina de Produção de Cibervídeos. Foram desenvolvidos usos pedagógicos, presencialmente e online, com os gêneros de vídeos mapeados, de forma a incitar nos praticantes da pesquisa a noção de autoria docente, mobilização de saberes para a produção audiovisual e compartilhamento em rede de suas produções.

Durante a pesquisa, algumas questões nos inquietavam, como: Quais as potencialidades dos vídeos na educação e mais especificamente na educação em tempos de cibercultura? E quais atividades podem ser desenvolvidas utilizando as interfaces digitais para potencializar a autoria de vídeos pelos docentes, tendo em vista a crescente atualização dos softwares, aplicativos e práticas audiovisuais na educação online?

A pesquisa-formação da cibercultura (Santos, 2014) foi o método escolhido para compreender os fenômenos educativos com usos de hipervídeos e as questões norteadoras mencionadas. $O$ método não separa o pesquisador do formador, ou seja, enquanto há uma ambiência formativa proposta pelo professor, ele está pesquisando os movimentos educacionais que acontecem, pesquisando a sua própria práxis docente, formando e se formando na troca com o outro.

A pesquisa parte de dilemas docentes, da relação com o aluno, das tensões com as práticas curriculares e com os processos políticos. Essa inquietação origina questões de estudos e então o docente aciona dispositivos de pesquisa (cursos, projetos ou ambiências formativas) para ir de encontro aos dados e compreender melhor o que causa a inquietude.

Após os processos educacionais, muitas narrativas (imagéticas, audiovisuais, sonoras e textuais) emergem, transformando-se em dados para que o pesquisador compreenda os fenômenos que o estavam inquietando. Em uma triangulação entre as questões norteadoras, o referencial bibliográfico e as vivências originárias do campo, há o resultado da pesquisa, em forma de

7 Foram três dispositivos de pesquisa: Oficina de produção de cibervídeos, Diário compartilhado e de gravações das apresentações dos trabalhos e das conversas posteriores. 
noções subsunçoras ${ }^{8}$. A noção que emergiu com a produção do hipervídeo foi a autoria de vídeos interativos, que será abordada a seguir.

\section{Autoria de Vídeos Interativos}

O vídeo interativo traz a possibilidade de ao visionar um determinado documento fílmico, o estudante ou o professor poder interagir acedendo a uma entrevista, a um detalhe técnico, a um pormenor visual ou qualquer outro tipo de informação complementar, que funcionam como âncoras e podem incrementar o valor didático do próprio vídeo (Moreira \& Nejmeddine, 2015, posição 153).

A autoria de vídeos interativos foi uma noção subsunçora que emergiu a partir das produções de cibervídeos como o webinar, a videoconferência, a videoaula e, em especial, o hipervídeo, refletindo sobre como é importante pensar em questões como a interatividade para a elaboração de vídeos na cibercultura, de forma a não tornar uma potência educacional em mais uma prática engessada. A narrativa da praticante Márcia sobre a interatividade no webinar corrobora essa perspectiva. Ela comentou a questão ao longo da sua apresentação:

Márcia: Eu tenho uma coisa para falar sobre a questão da interatividade e da interação. No webinar você pode convidar pessoas que você quer que participe por e-mail, então podemos participar, dependendo da plataforma, todo mundo aqui, e dependendo da conexão. E tem interatividade, você pode mandar perguntas, mesmo quem está assistindo. Eu estou entrevistando a professora Edméa e convido vocês para assistir ao webinar, e então, assim, vocês podem mandar perguntas digitando no bate-papo, quem é convidado interage no bate-papo, pelo chat. Então

\footnotetext{
8 Noções subsunçoras são o esforço para interpretar o que emerge do campo, o que se constrói e se aprende a partir da pesquisa, o que vem da empiria e da sua formação prévia. São noções que emergem da conversa com os dados, com a prática e com suas vivências, representam o que ficou de significativo após a pesquisa, na relação igualitária entre práticateoriaprática. Os resultados da pesquisa são originários do ato de reagrupar os elementos por noções subsunçoras, com sistematização textual e produção de uma nova interpretação do fenômeno estudado. (Santos, 2012).
} 
isso é legal, porque tem a questão do emissor e do receptor se tornarem interlocutores, como é destacada a importância na interatividade.

Durante uma entrevista para duas professoras mineiras, o professor Marco Silva fala que "Interatividade significa articulação da emissão e da recepção na cocriação da mensagem" (Silva, 2012, p. 5). E acrescenta que a internet evoluiu favoravelmente à interatividade, principalmente a partir da web 2.0, na lógica "todos-todos”. Já a TV e as mídias de massa ficaram no paradigma da transmissão "um-todos", o que não significa que o público da TV será sempre passivo, enquanto o usuário da internet será ativo.

Já observamos que as perspectivas evoluem e os usos tecnológicos são ressignificados a cada instante. Da mesma forma acontece com a educação, quando contamos com boas estruturas tecnológicas sendo subutilizadas. Para o autor "o compartilhamento, a conectividade, a interlocução, a colaboração e a liberação da autoria" (p. 7) são potencialidades interativas. Esses aspectos serão considerados para o nosso entendimento de vídeo interativo.

Santos e Silva (2014) ressaltam princípios básicos para construir a sala de aula interativa: "propiciar oportunidades de múltiplas experimentações e expressões", "disponibilizar uma montagem de conexões em rede que permita múltiplas ocorrências", "provocar situações de inquietação criadora”, “arquitetar colaborativamente percursos hipertextuais" e "mobilizar a experiência do conhecimento" (p. 55 e 56). Nos princípios acima, destacam-se noções importantes para pensar uma sala de aula interativa que foram consideradas na Oficina de Produção de Cibervídeos: perpassando ideias de experimentações com os audiovisuais, autorias de cibervídeos potentes para a educação online, audiovisuais em rede, promovendo conexões e hiperaudiovisualidades.

Para a construção da oficina, mapeamos e aprofundamos conhecimentos a respeito dos cibervídeos. A Oficina ocorreu em sete encontros no período entre 06 de outubro a 15 de dezembro de 2016. No encontro 1 abordamos as característica dos gêneros de cibervídeos, em um diálogo para explorar conhecimentos prévios e impressões sobre a temática. No encontro 2 , houve uma aula sobre roteirização audiovisual e no encontro 3, a elaboração do roteiro, do planejamento para a gravação e orientações técnicas sobre a pro- 
dução. Os demais encontros foram para as apresentações e as conversas sobre as produções.

Os grupos foram orientados a identificar os diferentes gêneros de cibervídeos, gravar os vídeos sobre as temáticas sorteadas, editar o recurso produzido através dos softwares indicados, divulgar o resultado do trabalho no YouTube, no Moodle e no grupo da disciplina no Facebook, e, durante a conversa presencial, apresentar um relato de experiência sobre as implicações, as dificuldades e os êxitos obtidos na produção do audiovisual.

Nesse sentido, emerge o Hipervídeo idealizado pelo grupo 6, denominado "Vídeos na Cibercultura". Não poderíamos deixar de destacar o hipervídeo ao falar sobre interatividade na produção audiovisual. Com uma abordagem cinematográfica, com a opção por planos, movimentos de câmera e angulações específicas inspiradas em filmes, o grupo contou uma história, simulando o encontro de duas alunas para um trabalho em grupo.

Ao longo do vídeo, demonstraram características da cibercultura, como as mídias sociais, uso de tablets e de aplicativos de mensagens instantâneas. As conversas são relacionadas ao audiovisual na educação, com dicas de livros sobre o tema e filmes clássicos. O vídeo discorre ainda sobre a história do cinema e sobre o conceito de hipervídeo, já que em cena, as personagens resolveram gravar um hipervídeo para um trabalho em grupo.

Hoje as produções profissionais e ate mesmo algumas produções amadoras criam suspenses com planos, enquadramentos. Não temos mais aquela situação de uma ou duas câmeras em plano conjunto, colocando o espectador na posição de simples observador. Os closes, planos detalhes e planos sequência tomam conta das narrativas audiovisuais, evidenciando que bebem nas fontes da linguagem cinematográfica (Agustoni, 2016, p. 116).

Outra perspectiva da hibridação trazendo peculiaridades da cibercultura para a produção audiovisual pode ser visualizada quando as autoras lançaram mão da linguagem do digital em rede para conceituar a estética do vídeo, na inclusão de mensagens de texto (Figura 1). Além dos recursos principais do hipervídeo, como as ligações internas e externas com conteúdos agregadores (Figura 2). 
FIGURA 1 - Captura da imagem do hipervídeo com acréscimo do aplicativos de mensagens instantâneas.

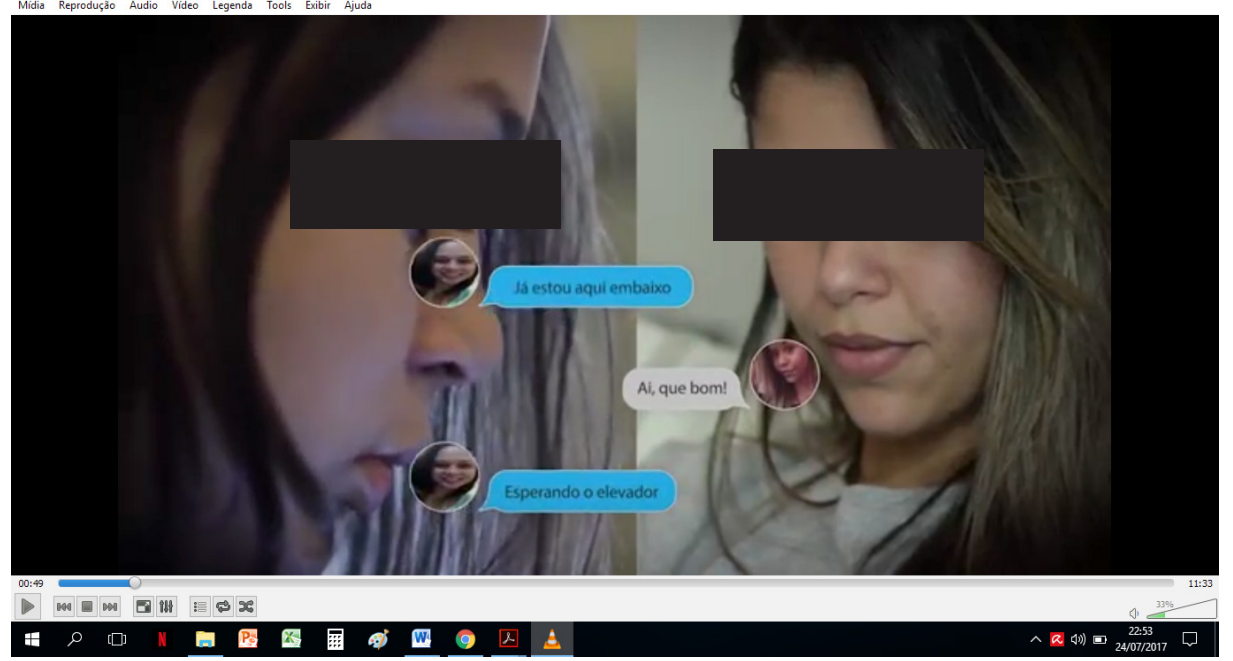

Fonte: https://www.YouTube.com/watch?v=sU2USSbr91s\&feature=youtu.be .

FIGURA 2 - Captura da imagem do hipervídeo na aparição do hiperlink.

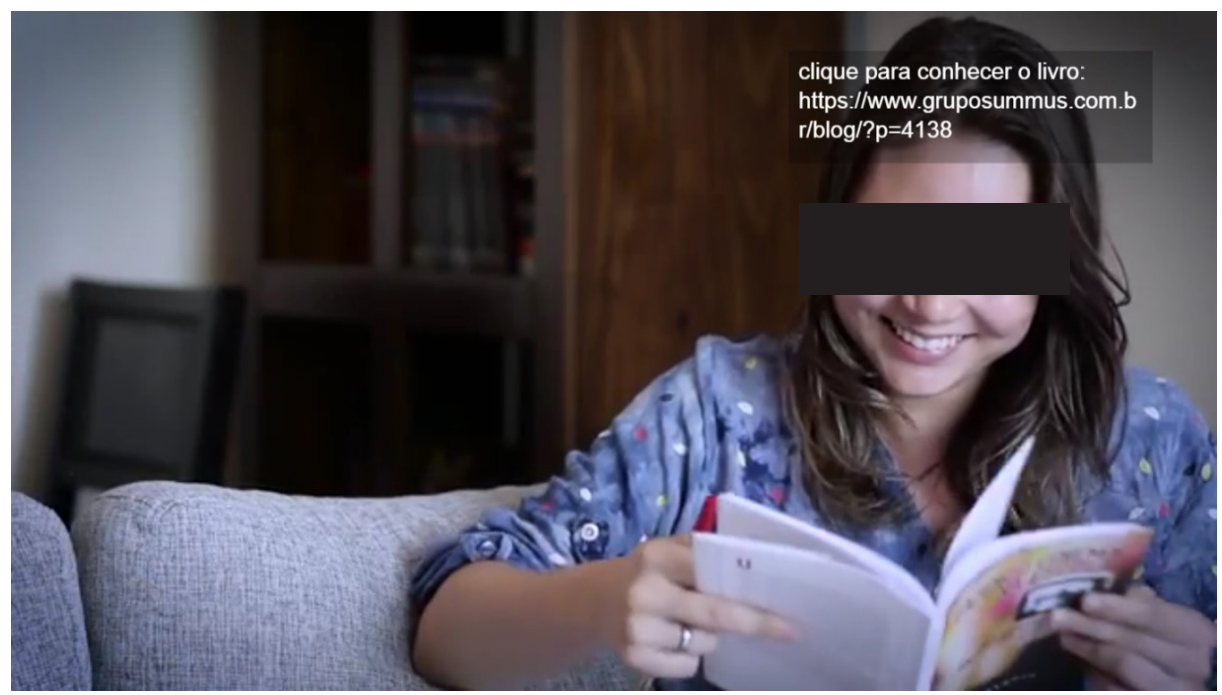

Fonte: https://www.YouTube.com/watch?v=sU2USSbr91s\&feature=youtu.be 
A captura da imagem da figura 2 foi realizada no momento em que um hiperlink foi disponibilizado. No vídeo, as praticantes citam um livro e recomendam a sua leitura, disponibilizando o link para conhecer o material. Essa é uma das possibilidades do hipervídeo e, dependendo da interface escolhida para produzir o cibervídeo, ela pode incluir outros recursos, como o YouTube, com a inclusão de outros vídeos, imagens, textos e hiperlink para qualquer conteúdo em rede. Ou seja, o hipervídeo pode ser elaborado de acordo com a necessidade ou o interesse do idealizador. Basta partir de uma premissa de autoria interativa de vídeos.

Os benefícios do hipervídeo na educação perpassam pela interatividade, conectividade, mixagem, hibridação, entre outros. A possibilidade de expandir os conhecimentos situados no vídeo para zonas internas ou externas e de reunir recursos diversos no mesmo suporte agregam à educação contemporânea. Podemos pensar que todos os gêneros de cibervídeos poderiam acrescentar características do hipervídeo, propondo práticas audiovisuais cada vez mais coerentes com a cibercultura.

\section{Conclusão}

Ao longo de um semestre trabalhamos com a turma de Tecnologias e educação da graduação em Pedagogia questões como a educação online e a autoria de vídeos, de forma a atingir o objetivo geral de compreender como os vídeos vêm se materializando e circulando na educação online, desenvolvendo práticas para a produção de gêneros de cibervídeos. O hipervídeo se destacou entre os gêneros abordados em uma Oficina de Produção de Cibervídeos pelo potencial interativo às praticas educacionais. Sendo um dos gêneros que mais se aproximava da cibercultura.

As questões norteadoras sobre as potencialidades dos vídeos na educação online e que atividades podem ser desenvolvidas utilizando as interfaces digitais para potencializar a autoria de vídeos pelos docentes foram trabalhadas com os praticantes e respondidas por eles e por mim ao longo da pesquisa, a oficina proporcionou um entendimento 
mais contextualizado sobre a produção de conteúdos e a formação de futuros docentes que considerem os recursos audiovisuais como possibilidades.

Durante o presente trabalho buscamos contextualizar o hipervídeo na educação online, proporcionando uma compreensão mais apurada de suas potencialidades. Retratamos os caminhos percorridos durante uma pesquisa-formação na cibercultura, indicando brevemente os passos da pesquisa. Como resultados, apresentamos a noção subsunçora que emergiu a partir das experiências vivenciadas na Oficina de Produção de Cibervídeos.

A intenção que ampara essa pesquisa-formação na cibercultura é a formação de docentes implicados com a produção de vídeos interativos para a educação online, de forma a desenvolver currículos praticados nos cotidianos educativos, levando a ações como: mesclar, bricolar, inventar, produzir, ressignificar (Amaro; Soares, 2016) para o horizonte vasto de possibilidades de suas carreiras.

Relatamos uma pesquisa implicada com a realidade que nos cerca, com os fenômenos que se manifestam nos movimentos da cibercultura. $\mathrm{O}$ hipervídeo não poderia ser mais contemporâneo, com os usos feitos pelos praticantes ciberculturais, torna-se uma potência para a educação online. Pensar na produção interativa de vídeos não significa direcionar somente para o hipervídeo, outros gêneros audiovisuais podem ser mesclados ou mixados, refletindo sobre a aprendizagem personalizada, em sintonia com as dinâmicas ciberculturais.

\section{Referências bibliográficas}

AGUSTONI, M. (2016). Convergências entre cinema e vídeo: contaminações e dissoluções limites. In. SANTAELlA, Lúcia. Novas formas do audiovisual. (pp. 108-121). 1. ed. São Paulo: Estação das Letras e Cores.

AMARO, I. \& SOARES, M. C. S. (2016). Tecnologias digitais nas escolas: outras possibilidades para o conbecimento. 1. ed. Petrópolis, RJ: DP et Ali.

BETTENCOURT, C. (2009). O hipervídeo aplicado à cibermuseologia. 132 f. (Dissertação de mestrado). Departamento de Comunicação e Arte. Universidade de Aveiro. 
MARTINS, V. (2017). Os cibervídeos na educação online: uma pesquisa-formação na cibercultura.. 179f. (Dissertação de mestrado) - Faculdade de Educação, Universidade do Estado do Rio de Janeiro.

MOREIRA, J. A.; NEJMEDDINE, F. (2015). O vídeo como dispositivo pedagógico e possibilidades de utilização didática em ambientes de aprendizagem flexíveis. Coleção Estudos Pedagógicos. 1. ed. Santo Tirso: Whitebooks.

SANTOS, E. O. (2014). Pesquisa-formação na cibercultura. 1. ed. Santo Tirso: Whitebooks.

SANTOS, E. O.; SILVA, M. (2014). A pedagogia da transmissão e a sala de aula interativa. Coleção Agrinho. Paraná. Disponível em: http://www.agrinho.com.br/site/ wp-content/uploads/2014/09/2_02_A-pedagogia-da-transmissao.pdf. Acesso em: 24 jul. 2017.

SARAIVA, A. J. (2013). Filme e hipervídeo: um retrato polifónico da geração dos Capelinhos a partir da emigração e regresso. 385f. (Tese de doutorado). Universidade Aberta Portugal.

SILVA, M. (2012). "Vivemos em um cenário midiático muito favorável à educação cidadã”. Entrevista a Carla Viana Coscareli e Ana Elisa Ribeiro. Presença Pedagógica. Belo Horizonte, v. 18, n. 106, 01-11. 